\title{
NO SOLO EL 23F. EL PSOE Y LA RACIONALIZACIÓN AUTONÓMICA (1978-1982)
}

Not only 23F. PSOE and the autonomic rationalization (1978-1982)

\author{
VEGA RODRÍGUEZ-FLORES PARRA' \\ Universitat de València \\ Vega.rodriguez@uv.es
}

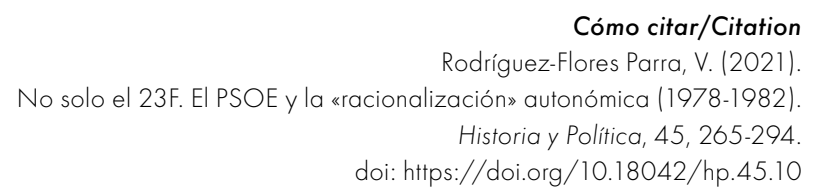

(Recepción: 09/01/2020; evaluación: 08/05/2020; aceptación: 13/07/2020; publicación: 01/06/2021)

\section{Resumen}

La firma de los Acuerdos Autonómicos por parte del PSOE y UCD en julio de 1981 ha sido interpretada tradicionalmente como consecuencia directa del frustrado golpe de Estado del 23F. Este artículo revisa este análisis a partir de documentación

1 La autora participa en los proyectos de investigación «Derechas y nación en época contemporánea. Una perspectiva transnacional»(PGC2018-099956-B-I00), del Ministerio de Ciencia e Innovación, cofinanciado con fondos FEDER, y «Estado y dinámicas nacionales en España (1931-1978)» (PID2019-105464GB-I00/ AEI/10.13039/501100011033). 
interna e inédita, atribuyendo la toma de posición del Partido Socialista, no solo a una reacción frente la intentona involucionista, sino como producto de un proceso mucho más amplio, iniciado tras la aprobación de la Constitución. Los socialistas, condicionados por su trayectoria ideológica, fueron elaborando una política en materia autonómica que estuvo marcada por la coyuntura y que dependió tanto de los avatares del contexto estatal como de los que afectaron a los procesos autonómicos de cada territorio. Cuestiones estratégicas, electorales, ideológicas y una actitud que trataba de conciliar posiciones relativas a la responsabilidad de Estado con el mantenimiento de promesas sobre las demandas de autogobierno, interactuaron retrasando un pacto sobre el que se debatió desde que el nuevo marco legal dejara abierta la nueva estructura del Estado. En esta investigación se analiza la coincidencia entre centristas y socialistas sobre la necesidad de racionalizar la construcción del futuro Estado de las autonomías desde 1979. De hecho, armonizar el proceso autonómico fue un objetivo fundamental en el PSOE mucho antes de que el 23F ofreciera a los socialistas la oportunidad idónea para alcanzar un acuerdo de Estado con el que diseñar un modelo coherente con los principios que el partido había defendido desde el inicio de la Transición.

Palabras clave

PSOE; Estado de las autonomías; Transición; 23F; LOAPA.

\section{Abstract}

The signing of the Autonomous Agreements by the PSOE and UCD in July 1981 has been traditionally interpreted as a direct consequence of the frustrated coup d'etat of 23F. This article, based on internal and unpublished documentation, revises this analysis, attributing the position of the Socialist Party, not only to a reaction against the intentional involvement, but as a product of a broader process, initiated after the approval of the Constitution. The socialists, conditioned by their ideological trajectory, were developing a policy on regional matters that was influenced by the situation and that depended on the vicissitudes of the state context and on those that affected the regional processes of each territory. Strategic, electoral, and ideological issues, and an attitude that tried to reconcile positions related to the "State responsibility» with keeping promises on the demands of self-government, interacted delaying a pact on which it was debated since the new legal framework left open the new structure of the State. This research analyzes the coincidence between centrists and socialists about the need to «rationalize» the construction of the future State of the autonomies since 1979. In fact, «harmonizing» the autonomous process was a fundamental objective in the PSOE long before that the $23 \mathrm{~F}$ offered the Socialists the ideal opportunity to reach a State agreement and design a consistent model with the principles that the party had defended since the beginning of the Transition.

\section{Keywords}

PSOE; State of autonomies; Transition; 23F; LOAPA. 
I. GENERALIZACIÓN O CONTENCIÓN: EL DILEMA AUTONÓMICO. II. PLANIFICAR LA RACIONALIZACIÓN... INTERNAMENTE. III. ¿UN ACUERDO POSIBLE? IV. LA RESPONSABILIDAD DEL 23F EN LOS ACUERDOS AUTONÓMICOS. V. CONCLUSIONES. BIBLIOGRAFIA.

¿Hasta qué punto el golpe de Estado del 23F fue el responsable de la firma de los Acuerdos Autonómicos entre UCD y PSOE en julio de 1981 y de la futura LOAPA? Probablemente se ha dado un peso excesivo a este suceso para explicar la racionalización del proceso autonómico y el papel que jugó en la misma el Partido Socialista, analizando aquel pacto casi exclusivamente como producto del miedo a una reacción involucionista que puso en peligro la consolidación democrática en España ${ }^{2}$. Otras veces, el simbolismo de aquel acontecimiento sencillamente ha ocultado el hecho de que la armonización fue en realidad fruto de un acuerdo nacido de la coincidencia de intereses y planteamientos entre el PSOE y la UCD, originado no en los albores de esta crisis, sino mucho antes. El 23F, en realidad, funcionó más bien como un catalizador y no como la causa de una toma de posición por parte del PSOE que venía fraguándose tiempo atrás. Aquel suceso ofreció la oportunidad idónea para que los socialistas pudieran explicar y justificar la necesidad de los acuerdos ante la sociedad, evitando perder por ello gran parte de su credibilidad. Así pues, el modelo pactado definitivamente en el verano de 1981 respondía a los deseos homogeneizadores que el PSOE había definido con anterioridad, como demuestra la documentación inédita consultada en el archivo y biblioteca de la Fundación Pablo Iglesias (ABFPI). En este sentido cabe resaltar la importancia que para esta investigación han tenido los fondos de acceso restringido con documentos relativos, entre otros, al Comité Ejecutivo, al Comité Federal o a la Secretaría de Política Autonómica, ocultos hasta ahora y que contienen, por ejemplo, actas de reuniones e informes internos en muchos casos confidenciales- que se preocupaban por definir la cuestión nacional, por establecer un esquema de prioridades, por fijar un calendario autonómico, que analizaban los resultados electorales o que se referían a la imagen pública del partido.

2 De la Granja et al. (2001): 203; Company y Arroyo (1989): 77; Gillespie (1991): 371-372; Rubio (2004): 66. 
El hecho de que la Constitución de 1978 hubiera dejado abierta la puerta a distintas interpretaciones sobre cómo debía construirse el futuro Estado de las autonomías había llevado al PSOE a situarse en una aparente indefinición o contradicción que el partido tuvo que ir resolviendo progresivamente. Así, fue improvisando en muchos casos una política autonómica que, en cualquier caso, estuvo motivada por los principios que habían guiado el pensamiento político del socialismo en torno a esta cuestión y que no nacían ex novo después de $1978^{3}$.

Además, conforme el PSOE se convirtió en una alternativa real de Gobierno, el partido fue moderando sus planteamientos en un proceso de «transición dentro de la transición»" en el que se fueron diluyendo las diferencias existentes entre el "programa máximo» y el "programa mínimo" 5 . De esta manera, las tesis proclives a racionalizar el Estado se vieron intensificadas especialmente a partir de la aprobación de los estatutos vasco y catalán —en el último tercio de 1979- ${ }^{6}$, cuando la voluntad de llegar a acuerdos con los centristas estaba muy presente en la dirección socialista. Pese a ello, los avatares de la coyuntura fueron impidiendo un pacto global con UCD que, aunque deseado, se veía en parte condicionado por las dinámicas estatales o por los intereses territoriales en lugares como Andalucía, Galicia o, en menor medida, el País Valenciano o Canarias. Aun así, como demuestra la documentación trabajada en esta investigación - y que permite revisar la interpretación habitual 7 - durante esta etapa, poco abordada por una historiografía más preocupada habitualmente por el periodo preconstitucional ${ }^{8}$, proliferaron estudios e informes que permitieron ir articulando un pensamiento teórico destinado a planificar la racionalización de la nueva ordenación territorial. Desde el socialismo se generó una respuesta al problema de la construcción del Estado de las autonomías que, incluso, situó al partido en posición de liderar el proceso frente a una UCD que fue, en ocasiones, a remolque.

Así pues, en estas páginas tratamos de demostrar que la defensa de un sistema autonómico simétrico y homogéneo sí era acorde a una trayectoria

3 Sobre el no olvido de España en el pensamiento socialista y comunista antes y después de 1978, Archilés (2009): 103-122; Núñez Seixas (2010).

4 Mateos: (2007): 285-299.

5 Juliá (1997); Andrade (2012).

6 Molinero e Ysàs (2014); Landaberea (2016); Miccichè (2009).

7 La historiografía que se ha ocupado de esta cuestión ha puesto el foco de atención en el verano de 1981, sin subrayar que fue en esta fase previa cuando se forjó el modelo que se pactó más adelante —Mateos (2017): 140-141; Quiroga (2009): 21-40—.

8 De Blas (1978): 155-170; Juliá (2013): 886-902; Molinero (2011): 235-256. 
previa en el PSOE que no nacía en ningún caso en 1981. Entonces los socialistas no hicieron más que culminar un proceso por el que habían estado transitando mucho antes.

\section{GENERALIZACIÓN O CONTENCIÓN: EL DILEMA AUTONÓMICO}

Sobre la generalización autonómica en España se ha debatido mucho, también entre los protagonistas políticos que la propiciaron. En el PSOE la crítica a este proceso se hizo común a partir de 1980, cuando comenzaron a responsabilizar a UCD, y especialmente a Manuel Clavero, de haber generado artificialmente las demandas de autogobierno en el conjunto de los territorios del Estado9. Alfonso Guerra atribuyó al ministro para las Relaciones con las Regiones el diseño del "café para todos», aunque reconocía que las políticas ejercidas por el Partido Socialista habían contribuido a extender el modelo en aquella "carrera «a pelo» para situarse como más regionalista que nadie» ${ }^{10}$.

En realidad, el PSOE se mostró favorable a extender la autonomía a todas las nacionalidades y regiones por cuestiones estratégicas, pero también por el convencimiento de que el derecho a la diferencia no podía menoscabar la igualdad en derechos de los territorios. Así, antes de que Clavero impulsara las preautonomías y diera luz verde a la generalización autonómica, que acabaría siendo interpretada como un lastre por su propio partido, los socialistas ya habían dado muestras de su preferencia por este modelo, incluso en el XXVII Congreso de diciembre de $1976^{11}$ o en las posiciones que defendieron ante el debate constitucional ${ }^{12}$. De hecho, según Gregorio PecesBarba, el primer anteproyecto de la ponencia, que no distinguía entre

9 Archilés (2016): 141-173; Sánchez (2009): 7-20.

10 Guerra (2004): 233-234. Dentro de UCD, otros como Martín Villa, que manifestó no estar de acuerdo con ese diseño del modelo de Estado al que llamaba la «tabla de quesos», también han responsabilizado de la generalización autonómica a Manuel Clavero (Martín Villa, 1984).

11 En su Resolución sobre nacionalidades se apostaba por que «se abra un proceso mediante el cual todas las nacionalidades y regiones que lo deseen puedan dotarse de sus propios regímenes de autonomía» (Guerra, 1977): 125-134.

12 Alejando Quiroga, sin embargo, defiende que fue después del anteproyecto cuando se produjo por parte del PSOE y del PCE la renuncia a «otorgar a Cataluña, el País Vasco y Galicia un estatus especial dentro de una España descentralizada». Si bien esto podría responder mejor al perfil del PCE, no encaja del todo para el PSOE que, aunque planteaba dudas a este respecto, no quería imponer ningún tipo de sistema asimétrico, más bien al contrario (Quiroga, 2009): 26. 
diferentes vías para el acceso a la autonomía, se debió fundamentalmente al empeño socialista:

Mi esfuerzo se dedicó durante toda la discusión a introducir elementos que nos aproximasen a ese federalismo funcional, que superaba la justificación de las autonomías como salida a la diferencia cultural de algunas nacionalidades, y la completaba con el criterio más racional u objetivo, válido para las demás regiones españolas, de la descentralización política y la distribución territorial del poder, que permitiría al final del proceso una igualdad entre todas las comunidades autónomas. No fue fácil, pero creo que en definitiva se alcanzó ese objetivo ${ }^{13}$.

El modelo pactado finalmente en la Constitución de 1978 no zanjó aquella discusión y dejó abierta la posibilidad de desarrollar un Estado simétrico - con la excepción de los casos vasco y navarro gracias a la disposición adicional primera- o asimétrico ${ }^{14}$. Se estableció el acceso a la autonomía a través, fundamentalmente, de dos vías: la «lenta» del artículo 143, en principio de menores competencias, y la «rápida» del artículo 151, que otorgaba las mayores cotas de autogobierno y que permitía a otros territorios igualarse desde el inicio a las llamadas nacionalidades históricas (que accedían directamente a esta vía por medio de la disposición transitoria segunda) ${ }^{15}$.

Aprobada la Constitución no cabe duda de que los socialistas se posicionaron proclives a la generalización autonómica y así se sancionó en la resolución sobre autonomías del XXVIII Congreso —en mayo de 1979-, en la que se manifestaba que era el PSOE el partido que debía liderar y animar la «eclosión» de la concienciación nacional o regional de los pueblos de España ${ }^{16}$. Pero este convencimiento no impedía que los socialistas alertaran sobre los peligros que provocaba la "carrera competencial», de modo que la elección de la vía del artículo 151 comenzó a plantearse con cautela. Desde la estructura federal, a partir de 1979 y sobre todo de 1980, se empezó a

Peces-Barba (1988): 43, 75, 83.

14 El modelo de organización territorial que consagró la Constitución y que permitía la generalización autonómica fue, en opinión de Carme Molinero y Pere Ysàs, fruto del acuerdo político entre la izquierda estatal, UCD y los nacionalismos subestatales (Molinero e Ysàs, 2018): 180-188.

15 Manuel Clavero asegura que fue su empeño personal por generalizar las autonomías el que propició la inclusión de la vía del artículo 151 (Clavero, 1983): 33-39, 103-106.

16 «Autonomías», en PSOE: Resoluciones. 28 Congreso, Archivo y Biblioteca la Fundación Pablo Iglesias (ABFPI), c 142, pp. 3-6. 
planificar el proceso autonómico con una visión global y con una concepción armonizadora que facilitaba un acuerdo de Estado en esta materia con el partido de Gobierno. Es en este contexto en el que nace - en el Congreso Extraordinario de septiembre de 1979- la Secretaría de Política Autonómica, dirigida oficialmente por María Izquierdo, aunque bajo la estrecha supervisión de Alfonso Guerra. El proyecto general, especialmente tras la aprobación de los estatutos vasco y catalán, se inclinaba a generalizar la vía del artículo 143 para pausar y graduar el proceso autonómico, sobre todo en aquellos territorios en los que la vía rápida no había sido reivindicada todavía o en los que dar marcha atrás no supondría excesivos costes políticos y sociales. No se trataba en ningún caso de crear comunidades de primera y de segunda, sino que la voluntad de los socialistas se orientaba más bien a hacer servir las dos vías para regular el acceso a la autonomía y evitar la precipitación, siempre bajo la premisa de que el horizonte de llegada sería el mismo para todos. La igualdad y la solidaridad eran fundamentales en el proyecto nacional del PSOE, y la posibilidad de reconducir la mayoría de los procesos por la vía lenta se planteaba solo para asegurar la unidad y la funcionalidad del Estado, pues el partido temía que con la «carrera competencial» se pusiera en peligro la joven democracia.

Sin embargo, aquella actitud proclive a llegar a acuerdos para racionalizar el proceso autonómico, se topó en enero de 1980 con el anuncio unilateral de UCD en el que comunicaba su voluntad de reconducir todos los procesos autonómicos por la vía del artículo 143, tratando, incluso, de recortar la autonomía gallega ${ }^{17}$. Aquel «hecho consumado» había obligado al PSOE, en palabras de Alfonso Guerra, a «situarnos en la actitud contraria, en la defensa de la vía rápida del artículo $151 »$, especialmente en Andalucía ${ }^{18}$. Allí, a diferencia de lo que sucedería en otros lugares, la reconducción no contó con el acuerdo del conjunto de la UCD regional, y aunque la Ejecutiva Nacional decidió recomendar la abstención en el referéndum del 28F, Manuel Clavero se opuso frontalmente ${ }^{19}$. Esta figura fue clave - aunque no determinantepara dificultar que la estrategia centrista triunfara y que el movimiento proautonómico se replegara, haciendo más difícil que los socialistas cedieran ante las presiones del Gobierno. Martín Villa ha contado cómo él y gran parte de la plana gubernamental presionaron a Suárez para que destituyera a Clavero, precisamente porque estaba siendo perjudicial, incluso de cara al pacto con los

17 Sobre el desbloqueo del autogobierno en Galicia y la dubitativa actitud socialista, véase Grandío (2015): 59-76.

18 Guerra (2004): 235.

19 Clavero (1980): 202-215. 
socialistas: «No era lógico que un ministro del Gobierno estuviera arrastrando a todos, también a la oposición socialista» ${ }^{20}$.

El cambio de posición centrista afectó especialmente a aquellos territorios que se habían pronunciado oficialmente por la vía rápida y que iban a sufrir desde entonces diversos obstáculos para acceder a la autonomía. Empezando por la aprobación en diciembre de 1979 de la «Ley Orgánica sobre regulación de las distintas modalidades de referéndum», que fue aprobada con el concurso del $\mathrm{PSOE}^{21}$. Esta ley requería del voto afirmativo de la mayoría de los electores de cada provincia para acceder a la autonomía por la vía del 151 , lo que hacía muy difícil obtener un resultado positivo, como sucedió en Andalucía, donde no se consiguió la ratificación de la consulta a causa del resultado en Almería, pese a que el $55 \%$ del total del censo andaluz se había pronunciado afirmativamente ${ }^{22}$. Pero la consecuencia más directa de esta ley, a pesar de que no se ha dado demasiada publicidad a esta cuestión, fue el hecho de que con ella se impidió la propia convocatoria del referéndum en Canarias y País Valenciano, aunque ambos territorios habían culminado con éxito la iniciativa autonómica ejercida por sus ayuntamientos tal y como había sido establecido en la Constitución. La nueva ley, impuesta de manera retroactiva, obligaba a que los pronunciamientos de los ayuntamientos se hubieran realizado haciendo constar de forma explícita la vía del artículo 151. Al mismo tiempo, territorios como Aragón o Baleares, donde este procedimiento todavía no se había llevado a cabo, veían cómo sería casi imposible acceder a la autonomía plena ante la negativa centrista y en condiciones legales tan desfavorables.

Desde el viraje de UCD en materia autonómica, el PSOE se convirtió en abanderado de la causa andaluza mientras trataba de reconducir, en la medida de lo posible, el resto de territorios por la vía del artículo 143, creando un clima de opinión favorable y tratando de ofrecer dos caras para no dañar su imagen pública ${ }^{23}$. Durante este tiempo, las negociaciones con el partido de Gobierno para solucionar el problema autonómico quedaron congeladas y aunque los socialistas escenificaron en algunos ambientes su preocupación por desbloquear los procesos autonómicos a partir de soluciones que

\footnotetext{
Martín Villa (1984): 183.

21 No sólo permitieron su aprobación, sino que en su elaboración se contó con la participación de Alfonso Guerra, Secretaría de Política Autonómica-PSOE: «Reunión con los secretarios generales de Nacionalidad y Región y otros responsables de política autonómica» (8 de enero de 1980), ABFPI, 075-E2, p. 11.

22 Sobre el bloqueo andaluz, Ruiz (2005); De los Santos (2002).

23 Secretaría de Política Autonómica-PSOE: «Bases de actuación en materia de política autonómica» (Madrid, 18 de enero de 1980), ABFPI, 75-B 9.
} 
respetasen la voluntad popular en lugares como Andalucía, Galicia - y en menor medida País Valenciano, Canarias, Aragón y Baleares-, internamente se estaba trabajando por «desdramatizar» lo que se reducía a una "cuestión procedimental».

Por otra parte, en esta fase hay que tener en cuenta otro hito que reforzó la postura proclive a racionalizar la construcción del Estado de las autonomías por parte del PSOE. Nos referimos a la derrota socialista en las primeras elecciones autonómicas en Cataluña y Euskadi. El balance en cuanto a los réditos que estaban obteniendo por su política autonómica era, como sus actitudes al respecto, irregular. Mientras que tras el referéndum del 28F en Andalucía todo parecía indicar que mejorarían los resultados de las elecciones de 1979 en este territorio ${ }^{24}$, las elecciones autonómicas en Euskadi y Cataluña de marzo de 1980 no ofrecían una perspectiva similar, dejando patente que no se había sabido remontar la situación de las generales en el País Vasco y que se habían hundido de forma inesperada en Cataluña. La Ejecutiva del PSOE demostró su preocupación ante el «revés» que habían supuesto estos resultados ${ }^{25}$, y como reacción el partido articuló una respuesta a partir de la cual, por un lado, se defendían los derechos autonómicos, cuya bandera se sentían legitimados a enarbolar gracias a su comportamiento ante la cuestión andaluza; y por otro, se hacía gala de una significativa prevención ante el nacionalismo. En el PSOE se comenzó a hablar sobre los peligros de la fragmentación de la estructura política española y el propio Felipe González llegaría a alertar sobre la posibilidad de que a partir de las elecciones de 1983 fuera difícil obtener mayorías a causa del auge nacionalista ${ }^{26}$. Por un lado, en su estrategia de enfrentamiento con UCD, Andalucía era tremendamente útil al socialismo, pero por otro se empezaba a desarrollar de forma más nítida una estrategia que conducía hacia la armonización, manteniendo lo que se consideraba era una política de Estado y que a la larga dificultaría o imposibilitaría el derecho a la libertad de elección de vía en el resto de territorios, y que afectaría también a las políticas autonómicas en el País Vasco y Cataluña ${ }^{27}$.

24 Así se demostró en la primera oportunidad en la que pudieron medir sus fuerzas en las urnas. En las elecciones parciales al Senado en las provincias de Sevilla y Almería de noviembre de 1980, el PSOE obtuvo los mejores resultados de su historia, El Socialista, 182 (del 3 al 9 de diciembre de 1980).

25 Véase un informe de mayo de 1980 citado en PSOE: «Memoria. Informe de gestión I. 29 Congreso", Madrid, 1981, pp. 10-12.

26 Citado en Alonso y Elordi (1982): 38.

27 Sobre el triunfo de Convergència i Unió en las urnas y la repercusión en el PSOE, Culla (1998): 104-105. 
Aunque la defensa socialista de una planificación autonómica centralizada no surgía a partir de aquellas derrotas electorales, el partido encontró gracias a ellas más motivos para anteponer la unidad estatal a otras cuestiones. De esta manera, en esta fase se agudizaron las tensiones entre una actitud proclive a defender los derechos de las nacionalidades y regiones, que proporcionaba, además, más elementos con los que oponerse al Gobierno, y otra que entendía que racionalizar el proceso autonómico era necesario y que para ello se debía llegar a un acuerdo con UCD.

\section{PLANIFICAR LA RACIONALIZACIÓN... INTERNAMENTE}

La posición autonómica del socialismo, a grandes rasgos, no estaba presentando unas directrices incompatibles con la voluntad racionalizadora de UCD, excepto en el tema andaluz que, a pesar de todo, tampoco colisionaba con este modelo unitario, aunque no uniformizador. $\mathrm{El}$ "problema andaluz» se convertía en este discurso en un "problema de Estado» que ofrecía una alternativa a la imposición de la unidad: la unidad voluntaria. Andalucía otorgaba al PSOE la posibilidad de presentar otra batalla frente al Gobierno, sobre la que la victoria estaba prácticamente asegurada. Manteniendo una estrategia de distanciamiento con la política de consenso, el PSOE se esforzaba por evitar las posibles coincidencias. La política de alianzas había sido debatida en el Congreso Extraodinario y se había impuesto la idea de que el partido debía evitar vincularse con el Gobierno para no erosionar su imagen a través de una política de acuerdos que se juzgaba había resultado perjudicial en las elecciones generales de marzo de 1979. Se consideraba que sin poder ejercer el control sobre ningún resorte del Ejecutivo ni sobre las políticas que implementara UCD, y sin contar tampoco con las contrapartidas que ofrecía participar directamente en la gestión, solo se conseguiría dañar la imagen pública del PSOE. Esta estrategia tenía, por otra parte, una salvedad, la que pudiera derivarse de una situación que requiriera la colaboración con el resto de las fuerzas parlamentarias ante un inminente peligro para la democracia, caso en el que su condición de partido de Estado se impondría, se decía, a la estrategia política ${ }^{28}$. Por ello, mientras se congelaron las conversaciones sobre el pacto, se comenzó a trabajar para alcanzar acuerdos en los distintos territorios.

En este contexto, durante el verano de 1980 se siguió perfilando la política autonómica del partido en las terceras jornadas organizadas por la Secretaría de Política Autonómica. Estas se nutrieron de reflexiones e informes que

28 PSOE: Resolución política del Congreso Extraordinario (Madrid, 28-29 de septiembre de 1979), ABFPI, Fc 261. 
fueron debatidos por bloques temáticos. De estos debates surgió el documento Esquema básico para la elaboración de un documento sobre las autonomias, que recogía los principales acuerdos y líneas de acción a seguir a partir de entonces, y que se inspiraba en los informes del diputado socialista Pedro Silva Las autonomías en la Constitución de 1978. Problemática que plantean y La vía socialista a la autonomía. La autonomía plena, además de en el documento Modelo institucional del Estado de las autonomías, elaborado a partir de una ponencia de Joan Prats, diputado socialista en el Parlamento catalán.

Los debates establecían como punto de partida inmediato la Constitución de 1978, en cuyos límites se situaba la política autonómica socialista. Se reconocía, por otra parte, «un poder político verdadero y propio» a las instituciones autonómicas, que constituían un poder del Estado, participando del ejercicio de la soberanía sin ser soberanas ${ }^{29}$. Se partía del reconocimiento de la voluntad popular de las comunidades, que había desencadenado los procesos autonómicos y que, por tanto, había impedido una planificación controlada del mapa autonómico. Hasta entonces se había mantenido la idea de que era esa voluntad popular la que debía determinar el volumen de competencias que cada comunidad adquiriría, pero en estos documentos se alertaba del riesgo de que esta dinámica provocara una «irreversible crisis del Estado». Una crisis causada — se decía — por una mala praxis de la libertad, pues si esta no se ejercía de manera responsable podría llegar a construir un «Estado asimétrico y permanentemente inacabado», totalmente disfuncional y con el que los socialistas no estaban de acuerdo ${ }^{30}$.

La respuesta del PSOE para evitar esta crisis partía de un desarrollo del Estado autonómico que conjugara el respeto a la voluntad de las comunidades autónomas con unos ritmos homogéneos. Prudencia para evitar el fracaso o la destrucción del Estado ${ }^{31}$. En este caso, la alusión al problema de las vías era directa, y aunque la idea de convertir en plena la vía del artículo 143 no resultaba una novedad, en estos momentos cobraba una importancia simbólica

29 Un análisis que derivaba de la conveniencia politica, ya que, como el propio Prats afirmaba: «Esta interpretación puede no corresponderse con la interpretación «auténtica» de la Constitución, pero es la impuesta por la dinámica autonómica y la que mejor se acomoda a la batalla política a la vez en el frente estatal y en el autonómico. Por lo demás, es la única que puede competir a nivel ideológico con los «nacionalismos» de las nacionalidades», en Joan PRATS: Modelo institucional del Estado de las Autonomias, ABFPI, 75-E 4.

30 Pedro Silva: Las autonomías en la Constitución de 1978. Problemática que plantean (10 de julio de 1980), ABFPI, 75-E 4, pp. 3-4.

31 Pedro Silva: La vía socialista a la autonomía. La autonomía plena (10 de julio de 1980), ABFPI, 75-E 4, p. 1. 
mayor, ya que esta declaración de intenciones quedaba plasmada ahora en un documento oficial. Con un apartado titulado como «La vía socialista: la autonomía plena», se declaraba que el «modelo socialista del Estado de las autonomías pone el acento en la configuración autonómica al final de los distintos procesos, y no en los aspectos propiamente procedimentales». Y a continuación se definían las que serían las bases del proceso armonizador: la generalización, la homogeneidad, la igualdad y la sincronización, intentando compatibilizar todo lo anterior con «la voluntad autoconstituyente de las Comunidades, que los socialistas se proponen impulsar en las direcciones referidas $\|^{32}$. No era cuestión de negar la voluntad de estas comunidades, pero ayudarlas a elegir la opción más conveniente, al parecer, sí era una obligación del PSOE.

Además, los socialistas se referían explícitamente al «problema de las dos vías», otorgándole un "carácter transitorio», en coherencia con la idea de no centrarse en los aspectos procedimentales, ya que se optaba por la construcción de un Estado simétrico y homogéneo en el que la igualación final quedaría asegurada. En este marco, se ignoró la vía del artículo 151, que quedaba negada al no ofrecerse ni tan siquiera como posibilidad, y la vía del artículo 143 quedaba fijada como "la vía ordinaria», convirtiéndola en una vía plena gracias a una «interpretación extensiva del art. $148 »^{33}$.

Por otra parte, este modelo necesitaba para imponerse «del concurso de una amplia mayoría en el proceso autoconstituyente», con lo que veían la «negociación como factor imprescindible en el desbloqueo del inicio de los procesos autonómicos ${ }^{34}$. Esto, aunque no lo expresaran abiertamente, significaba concertar las bases de los procesos autonómicos, ya fuera a nivel estatal o regional, con UCD como partido mayoritario. Y para hacer posible el acuerdo creían que en los territorios en los que se mantenía el bloqueo debían contribuir a «la desdramatización política del «conflicto de los procedimientosm", que era posiblemente el mayor obstáculo para la solución al problema, ya que al fin y al cabo la cuestión de las vías no era fundamental para el PSOE: «Hay que decir, en consecuencia, y no con afán de difuminar los conflictos, sino con el de asignarles su verdadera trascendencia y significado, que, desde nuestro acento en el final de los procesos, el procedimiento del artículo 143 es, simplemente, un régimen transitorio a la plena autonomía ${ }^{35}$. Algo en lo que, por otro lado, existía plena sintonía con la dirección

32 Secretaría de Política Autonómica-PSOE: Esquema básico para la elaboración de un documento sobre las autonomías, ABFPI, 75-E 4, pp. 4-5.

33 Ibid., p. 5.

34 Secretaría de Política Autonómica-PSOE: Esquema básico..., p. 5.

35 Pedro Silva: La vía socialista..., pp. 10-11. 
centrista. Rafael Arias-Salgado aseguraba que UCD solo estaba eligiendo una opción de procedimiento y que «el uso del artículo 143 iba a permitir un encauzamiento global del proceso autonómico, su ordenación racional, el establecimiento de ritmos adecuados y, sobre todo, alcanzar los mismos niveles autonómicos en todas las regiones y nacionalidades ${ }^{36}$. Punto sobre el que coincidiría el mayor artífice de la reconducción, Martín Villa, que explicaba la batalla entre el 143 y el 151 como un sinsentido, precisamente porque el modelo final que prefería su partido no conducía en ningún caso a la asimetría:

Eran los comienzos de la ridícula guerra entre los artículos 143 y 151 [...]. Se entendía por algunos que el acceder por la vía del artículo 143 suponía una autonomía «descafeinada», y la verdad es que no se pretendía que existieran comunidades autónomas de primera y de segunda. Al contrario, siempre he sido partidario de una cierta homogeneidad, sin la cual el proceso autonómico es imposible. Pero el procedimiento del artículo 151, pensado para situaciones excepcionales, era tan complicado que multiplicaba las consultas en forma realmente desorbitada. Su aplicación a todo el mundo nos hubiera podido conducir a una consulta popular cada veinte días entre 1980 y 1983. Intenté llevar al convencimiento [...] la idea de que con el artículo 143 se podían alcanzar idénticas competencias y poseer idénticos órganos de gobierno y representación ${ }^{37}$.

Volviendo a las jornadas de la Secretaría de Política Autonómica del PSOE, otro documento de José María Triginer —en este caso en un plano más teórico y de debate sobre las ideas $-{ }^{38}$ servía para fundamentar y explicar el porqué del modelo que se había escogido en el PSOE para el desarrollo del Estado de las autonomías. Ayudaba, además, a marcar distancias con los "nacionalismos alternativos», en coherencia con la nueva fase inaugurada tras las elecciones autonómicas. En él, el socialista catalán justificaba la búsqueda de la simetría a partir de una argumentación en la que el derecho a la diferencia se confundía con el derecho a la igualdad, que tenía que ver más bien con un concepto de la autonomía en el que la importancia recaía en la redistribución de recursos y el equilibrio socioeconómico (del que Andalucía se había convertido en el ejemplo paradigmático). A partir de aquí, Triginer

36 El Pais, 17 de enero de 1980.

37 Martín Villa (1984): 184. En un sentido similar el documento sobre las autonomías aprobado por el C. E. de UCD el 15 de enero, El Pais, 17 de enero de 1980.

38 Destacado dirigente del PSC-PSOE, vinculado al sector de la antigua Federación Socialista Catalana del PSOE. 
relacionaba la reivindicación de autogobierno con el sentimiento de «agravio comparativo", para el que la solidaridad era la única y mejor cura. Establecido esto, y buscando un espacio frente al nacionalismo conservador que controlaba las instituciones en Euskadi y Cataluña, añadía:

Por esas consideraciones somos contrarios a limitar nuestra actuación a nivel de región o nacionalidad. Eso solo sirve para polarizar la insatisfacción provocada por el «agravio comparativo» sin que se pueda ofrecer alternativas, que en todo caso se encuentran tanto en el propio ámbito de la "comunidad» como fuera de él, a través de la práctica de una auténtica solidaridad.

[...] La derecha tradicional, que ha dado su apoyo político al sistema capitalista, pretende traducir las justas aspiraciones de un pueblo en una política interclasista para diluir y mitigar la lucha contra el capitalismo ${ }^{39}$.

Se trataba de un discurso que proliferaría en territorios como Euskadi y Cataluña, donde el PSC-PSOE y el PSE-PSOE tratarían de rechazar un nacionalismo que calificarían como burgués y al que acusaban de haberse aliado con el Gobierno, en contra de los intereses de la clase obrera ${ }^{40}$.

Es evidente que, pese a mantener abierta una pugna que los socialistas tenían intención de ganar respecto a la vía del artículo 151 y Andalucía, en líneas generales el PSOE trabajaba por la consolidación del Estado a partir de una armonización y una ordenación territorial que asegurara la homogeneidad y la estabilidad, recelando cada vez más de los nacionalismos, especialmente en Cataluña y el País Vasco. Y es que, a partir de las elecciones de marzo de 1980, la influencia de la sensibilidad más vasquista en el PSE perdió ascendencia - en línea con lo que venía sucediendo desde la aprobación del Estatuto o incluso desde la misma campaña del referéndum-, y lo mismo sucedió con la que el nacionalismo catalán había ejercido en el PSOE hasta la inesperada derrota de las elecciones de marzo.

\section{III. ¿UUN ACUERDO POSIBLE?}

En septiembre UCD inauguraba una nueva etapa en materia autonómica en la que, tras la remodelación del Gobierno, sería Rodolfo Martín Villa

39 José María TRIGINER: Socialismo y autonomía, ABFPI, 75-E 4, pp. 3, 6-7.

40 Aquella ponencia sirvió, además, de base para generar otros documentos en los que se reforzó la crítica hacia los partidos nacionalistas, entre otros, María Izquierdo: Esquema sobre el Estado de las autonomías (26 de julio de 1980), ABFPI, 75-E 4. 
como nuevo ministro de Administración Territorial el encargado de reconducir las negociaciones sobre el desarrollo autonómico con el principal partido de la oposición, el PSOE. Y aunque desde septiembre se fue reforzando la decisión socialista de racionalizar el proceso autonómico en España, se siguió escenificando la existencia de un enfrenta miento mientras las posturas estaban cada vez más cerca ${ }^{41}$. Precisamente el 1 de octubre se realizó un encuentro entre Suárez y González para encontrar soluciones al problema autonómico, y aunque no se alcanzó un acuerdo oficial, existía sintonía entre ambos partidos. Pero la definición del conjunto del modelo quedaba aplazada hasta la resolución, en primer lugar, del problema andaluz, y después, del gallego ${ }^{42}$.

En cualquier caso, en los días previos a aquella reunión se fue clarificando la posición socialista respecto a los territorios en los que existía un mayor conflicto. Con fecha de 30 de septiembre se elaboraba el documento interno Estado de los diferentes procesos de acceso a la autonomía, en el que se hacía un balance de la marcha de los procesos autonómicos. Comenzando por Canarias, hay que aclarar que en aquellos momentos en la federación socialista — tras la celebración de su Congreso Extraordinario en mayo de 1980 - se había impuesto la posición pragmática del sector proclive a la vía lenta, liderado por Jerónimo Saavedra, reelegido entonces secretario general del PSC-PSOE ${ }^{43}$. Acorde a esta situación, en el documento mencionado se explicaba que en los últimos intentos de negociación con UCD, a lo largo de aquel mes, no existía posibilidad de convergencia. Pero la causa no era en ningún caso la vía, ya que explícitamente se aceptaba la del artículo 143 por ambos partidos, sino que el mayor escollo se encontraba en el sistema electoral ${ }^{44}$. Sin embargo, poco después se entraba en una nueva fase de negociaciones en este territorio en las que se exploraba una vía "específica» que, sin recurrir al artículo 151, otorgara las máximas competencias a Canarias, igualando el proceso al de Cataluña o Euskadi ${ }^{45}$.

41 Así sucedió ante la moción de confianza, pese a que el programa socialista preparado para la misma no era incompatible con el de UCD, Secretaría de Política Autonómica-PSOE: Informes Secretaría ante voto de confianza 16/9/1980, ABFPI, 75-G 3.

42 El socialista canario Luis Fajardo Spinola confirma que, pese a que comenzó a hablarse del resto de comunidades, las «conversaciones estaban principalmente dirigidas a desbloquear la situación andaluza» (Fajardo, 2009): 104.

43 Martín (1987); El Pais, 3 de junio de 1980; ABC, 3 de junio de 1980.

44 Secretaría de Política Autonómica-PSOE: Estado de los diferentes procesos de acceso a la autonomía (30 de septiembre de 1980), ABFPI, 75-B 9, p. 5. Ni siquiera en la prensa se planteaba la cuestión de la vía del 151, y en todo caso los socialistas hacían referencias a «no descartar» la del 144, El País, 30 de septiembre de 1980.

45 El Pais, 5 de octubre de 1980. 
Respecto a Aragón, los socialistas aceptaban negociar el acceso por la vía del 143 siempre que se dieran garantías de que en el plazo de cinco años se obtendrían los mismos techos que con la del 151 . Una vez más, la discusión se encontraba en el tipo de autonomía y no en los "procedimientos»" Para Baleares, donde no se había emprendido el proceso de iniciativa autonómica, la Federación Socialista Balear se negaba a comenzarlo hasta que no se obtuvieran «las debidas garantías de obtener un Estatuto con un techo competencial y un sistema electoral aceptable, siendo así se aceptaría adherirse a la vía $143 »^{47}$.

El caso del País Valenciano, sin embargo, era diferente, ya que en este territorio no se habían realizado, como en el resto, afirmaciones con las que expresamente se renunciara a la vía rápida. Tampoco se había hecho en aquel documento interno, en el que se demostraba la incertidumbre sobre cuál era la estrategia que se debía aplicar en esta región. En todo caso parecía que el partido estuviera esperando a que los acontecimientos fueran definiendo el panorama para entonces ir estableciendo directrices más precisas ${ }^{48}$. En esta región la situación se estaba revelando especialmente compleja, pues a diferencia de lo que había sucedido en Andalucía los centristas valencianos sí aceptaron reconducir la autonomía por la vía del artículo 143. Para ello, UCD dio alas al movimiento anticatalanista, generando un clima de violencia que desgastó en buena medida las posiciones autonomistas de la izquierda mayoritaria. Este contexto convulso explicaba que, aunque oficialmente no existieran negociaciones con UCD en esta nacionalidad, los socialistas tampoco hubieran protestado ante la declaración de los centristas - a través del presidente del Consell Preautonòmic ${ }^{49}$ — situando al País Valenciano, de facto, en la vía del artículo 143 .

Mientras se iba clarificando el panorama territorio por territorio, desaparecieron los que parecían ser los mayores obstáculos para resolver la cuestión del desarrollo autonómico de manera centralizada: los bloqueos de las autonomías andaluza y gallega. El 23 de octubre se firmaron los acuerdos que permitían solucionar el problema andaluz; y el 29, gracias al llamado Pacto del Hostal, una Comisión Constitucional permitió que Galicia tuviera una autonomía comparable a la de las otras dos nacionalidades históricas.

46 En sentido similar se pronunciaba el secretario general de los socialistas aragoneses, Santiago Marraco, El Pais, 26 de octubre de 1980.

47 Secretaría de Política Autonómica-PSOE: Estado de los..., pp. 6 y 17.

48 Ibid., p. 7.

49 Realizada por Enrique Monsonís el 29 de septiembre tras una reunión con Martín Villa. 
El camino de la reconducción y del pacto se había allanado. En apariencia nada obstaculizaba ya la armonización deseada tanto por el PSOE como por UCD - aunque diseńada por ambos partidos con diferencias notables-. Pero una vez más, la coyuntura política y la resistencia por parte de algunos sectores - socialistas y no socialistas - dentro de los territorios que se habían decantado de forma satisfactoria por la vía del artículo 151, iban a complicar aquel desenlace. El nuevo escenario trasladó el foco de interés hacia el País Valenciano, Canarias y, en menor medida, Aragón y Baleares, con un cambio significativo frente a la etapa anterior: la solución no se planteaba individualmente, sino en el marco de una planificación que armonizara el conjunto del Estado y que por aquel entonces pasaba preferiblemente por la reconducción de todos, o casi todos los territorios, por la vía del artículo 143 .

De momento, en documentos internos difundidos en noviembre los socialistas habían asumido el planteamiento oficial del Gobierno que legitimaba la aplicación a posteriori de la ley sobre modalidades de referéndum, aceptando que en Canarias y País Valenciano no se habían cumplido las exigencias de ninguna de las dos vías ${ }^{50}$. Algo que no era compartido en muchos sectores, especialmente dentro del territorio valenciano, lo que había animado al grupo parlamentario comunista a presentar — sintomáticamente el día nacional del País Valenciano, el 9 de octubre- una proposición de ley para modificar la Ley de diversas modalidades de referéndum. Esta proposición indicaba que la aplicación retroactiva de dicha ley «no sería en tal caso aplicable a Canarias y País Valenciano», ya que habían concluido afirmativamente sus procesos de iniciativa autonómica por la vía del $151^{51}$.

La iniciativa comunista estuvo presente en los debates en el seno del PSOE y del PSPV-PSOE, pero no se supo o quiso responder a la misma - ni a otras- al menos durante los meses de octubre, noviembre y buena parte de diciembre, en los que planeaba la posibilidad del pacto con $\mathrm{UCD}^{52}$. De hecho, a principios de noviembre tenía lugar un acercamiento entre las estructuras estatales de UCD y PSOE. Los centristas habían recogido el guante que había lanzado Felipe González para desarrollar el título VIII de la Constitución por medio de una ley orgánica que tuviese en cuenta el conjunto del Estado, y no

50 Secretaría de Política Autonómica-PSOE: Especial responsables. El Estado de las Autonomias (noviembre de 1980), AHUV (Arxiu Històric de la Universitat de València), Fons Alfons Cucó, 029, p. 15.

51 BOCG: Proposiciones de ley, n. ${ }^{\circ}$ 111-I, 30 de octubre de 1980, p. 420.

52 Emilio Attard declaraba: «Me consta que hay relaciones de verdad a muy alto nivel para llegar a un acuerdo consensuado. Tengo fe que terminarán bien», El País, 26 de octubre de 1980. 
a partir de una negociación individual con cada territorio ${ }^{53}$. En una reunión del PSOE del 10 de octubre entre Felipe González, María Izquierdo y los secretarios generales de las nacionalidades, se explicaba que las conversaciones con los centristas estaban avanzadas y que la UCD se estaba «aproximando en gran medida a nuestras posiciones, tanto a nivel estatal como en el ámbito de cada Comunidad. Necesitan más un pacto autonómico que nosotros; tenemos que aprovechar esta circunstancia». Y en las conclusiones —escritas desde la perspectiva de un mes más tarde ${ }^{4}$ —, los secretarios generales del País Valenciano, Canarias y Aragón aceptaban que el pacto autonómico global supusiera la reconducción de los tres territorios, pero a cambio demandaban que se les reconociera algún elemento diferenciador respecto al resto ${ }^{55}$. Así pues, no existían grandes incompatibilidades entre la propuesta socialista y la del Gobierno, que entre otras cosas pretendía reconducir todas las iniciativas autonómicas por el artículo 143, aplicando el artículo 150.2 de la Constitución para homogeneizar los distintos estatutos, de modo que alcanzaran las competencias del artículo 151, desbordando las que en principio correspondían a la vía lenta ${ }^{56}$.

En este ambiente, el día 12 de noviembre se celebró la primera de distintas reuniones entre la Ejecutiva Federal, representada por María Izquierdo y Alfonso Guerra, y los comités regionales del PSOE en Aragón, País Valenciano, Canarias y Baleares. Estas venían motivadas por la búsqueda de una estrategia global para desbloquear el acceso a la autonomía en los distintos territorios a partir de la propuesta del Gobierno. Según informaba El País, se había decidido «aceptar el hecho de que no se han alcanzado pronunciamientos suficientes para ninguna de las dos vías y que es necesario promover un procedimiento especial para estas cuatro comunidades», lo que provocaba reticencias entre los socialistas valencianos, partidarios en realidad de modificar la ley de modalidades de referéndum ${ }^{57}$. A pesar del acuerdo, la cuestión valenciana todavía fue planteada en términos problemáticos en los siguientes

53 El País, 6 de noviembre de 1980.

54 Documento elaborado en realidad el 11 de noviembre para preparar la reunión prevista para un día después en la que trataron los procesos autonómicos del País Valenciano, Canarias y Aragón, aunque para ello se sintetizaba la mencionada reunión del 10 de octubre.

55 Secretaría de Política Autonómica-PSOE: Notas previas a la reunión del día 12-11-80 sobre los procesos autonómicos del País Valenciano, Canarias y Aragón (Madrid, 11 de noviembre de 1980), ABFPI, 82-C 1, pp. 1-2.

56 El Pais, 6 de noviembre de 1980.

57 El País, 27 de noviembre de 1981. 
debates $^{58}$, entre otras cosas porque encima de la mesa y sin resolver se encontraba la proposición de ley de los comunistas, que perseguía una solución por la vía del artículo 151 en Canarias y el País Valenciano ${ }^{59}$.

En este clima se elaboró la Propuesta para el desbloqueo de los procesos autonómicos del País Valenciano, Canarias, Aragón y Baleares, en la que se habían tenido en cuenta proyectos de UCD y del Gobierno ${ }^{60}$. Presentada junto a unos anexos sobre el cálculo de repartición de escaños en los parlamentos regionales - tema que preocupaba entonces más que el de las vías-, solo quedaba en suspenso el caso valenciano. De hecho, el proyecto de desbloqueo para este territorio era abordado a partir de dos hipótesis. La primera, la modificación de la ley orgánica de referéndum para acabar con su retroactividad, afirmada solo como posibilidad para esta región. Aunque esta no parecía ser, sin embargo, la opción más plausible o deseada. Contaba con un mayor desarrollo la opción B: considerar que los pronunciamientos del 151 son válidos para el 143. Esta sería la vía negociada, de la que no agradaba, sobre todo, que posicionara a UCD como líder del proceso ${ }^{61}$. En el resto de proyectos se daba por terminada la batalla de las vías, ignorando tan siquiera su referencia, a excepción del referido a Canarias, en el que sorprendentemente se negaba que este territorio tuviera acreditado el proceso requerido para acceder a la vía rápida ${ }^{62}$.

58 Mientras que las negociaciones ya estaban avanzadas en otros territorios, en el País Valenciano no comenzaron oficialmente hasta noviembre, como se confirma en una reunión interna de la Secretaría de Política Autonómica, Secretaría de Política Autonómica-PSOE: Información sobre la situación del proceso autonómico en cada comunidad, ABFPI, 75-E 2.

59 De hecho, la existencia de esta iniciativa fue tratada con preocupación en las reuniones del 12 y del 18 de noviembre, Notas sobre la reunión del 18 de noviembre, ABFPI, 82-C 1.

60 Ministerio de Administración Territorial-Secretaría de Estado para las Comunidades Autónomas: «Proyecto de Ley Orgánica para hacer posible la igualdad y homogeneidad de las facultades y competencias de las Comunidades Autónomas», ABFPI, 74-G 3; UCD: Relación de temas que deben ser objeto de análisis conjunto, ABFPI, 74-G 3, p. 2.

61 PSOE: Propuesta de desbloqueo del proceso autonómico del País Valenciano (Madrid, 17 de diciembre de 1980), ABFPI, 74-G 3.

62 PSOE: Propuesta de desbloqueo del proceso autonómico Canario (Madrid, $17 \mathrm{de}$ diciembre de 1980), ABFPI, 74-G 3; PSOE: Propuesta de desbloqueo del proceso autonómico aragonés (Madrid, 17 de diciembre de 1980), ABFPI, 74-G 3; PSOE: Propuesta de desbloque del proceso autonómico balear (Madrid, 17 de diciembre de 1980), ABFPI, 74-G 3 . 
Pero el consenso sufrió, de nuevo, un paréntesis entre finales de diciembre hasta el intento del golpe de Estado del 23 de febrero. Durante este periodo, a los problemas que suponía la negociación del desbloqueo en el País Valenciano se sumaron otros surgidos en Canarias. Al parecer, la UCD no había aceptado una enmienda socialista al texto autonómico sobre la neutralidad militar, lo que había desembocado en una crisis entre los dos partidos del archipiélago y en la vuelta al bloqueo de su proceso autonómico ${ }^{63}$. En esta situación, un PSOE que se sabía fuerte y que ya había expresado que UCD necesitaba más el pacto que ellos, empezó a tensar la cuerda con declaraciones públicas sobre el posible boicot a un proyecto de ley por el que UCD pretendía garantizar la igualdad de competencias entre comunidades ${ }^{64}$. Detrás de esta reacción, en realidad se encontraba la estrategia de tensión a la que los socialistas querían someter a UCD. El pacto autonómico que estaba dispuesto a firmar Martín Villa había dejado excluida la posibilidad, que sí se barajaba en medios socialistas, de un acuerdo de Gobierno ${ }^{65}$. Ya a mediados de septiembre, Felipe González, escenificando la estrategia del PSOE como alternativa de Gobierno, afirmaba: «Mientras yo siga siendo secretario general del PSOE, este partido no volverá a firmar pactos con UCD extramuros del poder ejecutivo» ${ }^{66}$. Una actitud refrendada a principios de noviembre, cuando aseveró que solo concebía un acuerdo sobre el desarrollo autonómico en el marco de una operación política global ${ }^{67}$. Esta estrategia, unida a las muestras de desgaste del Gobierno de Suárez, propició que la dirección socialista se decantara por aplazar el acuerdo. Los socialistas querían aprovechar a su favor, además, la crisis de Gobierno, que alcanzaría su momento más álgido con la dimisión de Suárez el 29 de enero de 1981.

Fue durante este giro de los acontecimientos, que hacía que el acuerdo entre UCD y PSOE se pusiera en duda, cuando el problema de las vías iba a reaparecer de la mano del País Valenciano. El clima de consenso se vino abajo también entre las formaciones valencianas, que paralizaron las negociaciones. En este contexto, el PSPV-PSOE anunció la presentación de un proyecto de modificación de la ley de modalidades de referéndum «con el único objetivo de desbloquear el proceso autonómico del País Valenciano» ${ }^{68}$, extremo confir-

3 El País, 31 de diciembre de 1980; El País, 10 de enero de 1980.

64 El País, 27 de diciembre de 1980.

65 Así lo había confirmado el ministro de UCD, El País, 6 de noviembre de 1980.

66 Intervención realizada en la Escuela de Verano de 1980, El Socialista, 170 (del 10 al 16 de septiembre de 1980).

$67 \quad$ El Pais, 5 de noviembre de 1981.

68 El Pais, 24 de enero de 1980. Se dio luz verde a aquella estrategia en una reunión entre Joan Lerma, Felipe González y María Izquierdo a mediados de enero, Notas 
mado posteriormente por María Izquierdo ${ }^{69}$. Esta actuación servía a los socialistas, además, para hacer frente al PCPV, que con su propuesta de ley sí estaba demostrando su sensibilidad valencianista. Los socialistas buscaban de esta manera no sólo incrementar su espacio electoral a costa de UCD, sino hacerlo también gracias a la crisis del $\mathrm{PCE}^{70}$.

A mediados de febrero, un Partido Socialista que buscaba rentabilizar la crisis de UCD demostraba su nula intención de ofrecer al Gobierno un balón de oxígeno con la firma de un acuerdo sobre el modelo de Estado, al menos en lo inmediato: «Si no cometemos graves errores en el futuro inmediato, ante el país se ha abierto con mayor fuerza y con más confianza que nunca hasta ahora, la posibilidad de que los socialistas puedan ser el núcleo fundamental de un Gobierno capaz de estabilizar la democracia y de hacer avanzar el proceso ${ }^{71}$.

\section{LA RESPONSABILIDAD DEL 23F EN LOS ACUERDOS AUTONÓMICOS}

El frustrado golpe de Estado del 23F tuvo lugar en un contexto de paréntesis dentro de un clima de entendimiento entre el Gobierno y el PSOE. Así, aunque las cuestiones relacionadas con la ordenación territorial incidieron en sus causas, no parece razonable, a la luz de lo expuesto, explicar los Acuerdos Autonómicos como consecuencia del golpe. En todo caso, el 23F creó la oportunidad y las condiciones favorables para que culminara un acuerdo cuyos presupuestos básicos eran compartidos por los dos partidos mayoritarios desde finales de 1979. Así pues, aquel suceso actuó como catalizador de unas negociaciones que, esta vez sí, culminarían de manera exitosa.

El PSOE se vistió con el traje de la responsabilidad de Estado, labrándose una imagen que había perseguido ávidamente desde 1979 y que ahora podía

manuscritas (17 de enero de 1979), ABFPI, 79-D 3. BOCG: Proposiciones de ley, n. ${ }^{\circ}$ 125-I, 24 de febrero de 1981, pp. 453-454

69 La secretaria de Política Autonómica aclaró que la autonomía de Canarias estaba pendiente de la interpretación del presidente del Congreso de los Diputados acerca de la vía elegida por esa comunidad, El País, 27 de enero de 1980.

70 El PSOE pasó a considerar, en un documento fechado el 16 de febrero, como anticonstitucional la vulneración de la libre opción de vías, Secretaría de Política Autonómica-PSOE: Principales gestiones de los Ministros de Administración Territorial por orden cronológico desde 1977 (Madrid, 16 de febrero de 1981), AHUV, Fons Alfons Cucó, 029.

71 Informe de gestión presentado al Comité Federal el 28 de febrero de 1981, aunque escrito antes del golpe de Estado, PSOE: Memoria. Informe de gestión I..., p. 14. 
representar más que nunca. Alfonso Guerra declaró en 1985 que ante el abandonismo del Gobierno el PSOE tuvo que anteponer «su patriotismo solidario en defensa del sistema a sus intereses de partido». Y la firma de los Acuerdos Autonómicos fue una de las consecuencias más visibles de esta situación, ya que, según este político, la «revertebración de España» era una «de las piedras de toque de la consolidación definitiva del sistema» ${ }^{72}$.

Antes de esto, los socialistas ofrecieron un Gobierno de coalición a Calvo Sotelo, bajo el presupuesto, aprobado en su Resolución Política del Congreso Extraordinario, de la existencia de un peligro de «extrema gravedad para la perduración del sistema democrático» ${ }^{73}$. La situación excepcional había llegado, y por ello, el Comité Federal aprobó una resolución política el 1 de marzo en la que repetía su propuesta de Gobierno «con amplia mayoría parlamentaria y extenso apoyo social» que pudiera afrontar los principales problemas de España, entre los que se encontraba la «construcción solidaria de las Autonomías ${ }^{74}$. El ofrecimiento, pese a todo, no excluía otro tipo de acuerdo, como anunció el 25 de febrero Felipe González, en un discurso previo a la investidura del nuevo presidente ${ }^{75}$.

La proposición de formar un Gobierno de coalición fue rechazada por Calvo Sotelo, que temía la desestabilización que esto podría provocar en el interior de su propio partido, ya muy dividido, y apostó por una «política de concertación", que pronto involucró al Partido Socialista ${ }^{76}$. Desde el principio estuvo claro que esto incluía, como paso inmediato, la negociación del sistema autonómico, por lo que, en la reunión del Comité Federal del 28 de febrero y del 1 de marzo se estableció la obligación de "clarificar, definitivamente, la postura del PSOE ante el proceso autonómico, DESBLOQUEANDO Aragón, Canarias ${ }^{77}$, Valencia $»^{78}$. Y para ello fue necesario abandonar la

72 Guerra (1985): 13.

73 PSOE: Resolución Política del Congreso Extraordinario..., p. 11.

74 «Resolución Política» publicada en PSOE: Memoria. Informe de gestión II. 29 Congreso, Madrid, 1981, p. 59. En aquella reunión del Comité Federal, los días 28 de febrero y 1 de marzo, se insistió en que «no hay que caer en el error de una colaboración fuera del Gobierno. El Partido tiene que hacer todos los esfuerzos posibles por entrar en el Gobierno» (reunión del 28 de febrero de 1981), PSOE: Memoria. Informe de gestión II..., p. 24.

75 El Socialista, 195 (del 4 al 10 de marzo de 1981).

76 Calvo Sotelo (1990): 41.

77 Los socialistas retornaron a la Junta en una muestra de buena voluntad, El Socialista, 198 (25 al 31 de marzo de 1981).

78 Comité Federal del PSOE: «Anexo n.o 1. Propuestas de acción política en relación con la oferta socialista», AFFLC, Fondo PSOE. Partido Socialista Obrero Español, 004061-002. 
reivindicación de la vía del 151 para el País Valenciano, olvidándose, en consecuencia, de la proposición para modificar la ley de referéndum ${ }^{79}$.

Los primeros contactos de las negociaciones entre UCD y PSOE se produjeron en marzo. Leopoldo Calvo Sotelo ha escrito en sus memorias que ya en aquellos días encontró una fuerte sintonía con el líder socialista ${ }^{80}$. La sensación en Felipe González no sería la misma. De las primeras reuniones extraería la conclusión, que se mantuvo durante todo el proceso, de que el Gobierno no tenía iniciativa ni programa y de que, aunque el presidente del Gobierno veía en las autonomías un tema urgente, al creer que era el problema que más «irritaba» a los militares, se desentendía en materia práctica reconociendo "entender poco" del tema, delegando por tanto este asunto en Martín Villa ${ }^{81}$. El propio Calvo Sotelo reconocía después que, tras el affaire andaluz «nadie, ni en el Gobierno, ni en UCD, ni en la oposición tenían las ideas claras» ${ }^{82}$. Pero este hecho fue visto en parte como una oportunidad por los socialistas, ya que, conscientes de que no podían realizar solo una política de oposición, y aceptando que la única alternativa posible era la de la concertación, la «no oferta» les permitía al menos llevar la iniciativa, pese a que en realidad fuera una tarea que correspondía al Gobierno.

Por otra parte, mientras el Ejecutivo gestionaba la posibilidad de organizar un equipo de técnicos para que elaborara un primer informe, el aparato del PSOE asumió rápidamente su nuevo cometido y preparó una campaña extraordinaria "por la libertad y la Constitución», en la que se esgrimió la necesidad de una política conjunta con el Gobierno para prevenir actitudes anticonstitucionales, lo que en materia autonómica significaba "poner fin definitivamente a las tendencias centrífugas» y construir un modelo de Estado autonómico «tan firme y tan fuerte como pueda serlo un Estado centralista»,

79 También sucedió así en el PCE, y la proposición comunista fue retirada del Congreso el 17 de marzo de 1981. Los socialistas no lo hicieron hasta el 9 de septiembre de 1981, mucho más tarde de que la vía del 151 fuera descartada. Véase, respectivamente, BOCG: Proposiciones de ley, n. ${ }^{\circ} 111-\mathrm{I} 1,28$ de marzo de 1980, p. 420/1; y BOCG: Proposiciones de ley, n. ${ }^{\circ}$ 125-I 1, 18 de septiembre de 1981, pp. 454/1.

80 Calvo Sotelo (1990): 107. Únicamente hemos encontrado referencias a cómo se gestaron los Acuerdos Autonómicos desde la perspectiva centrista en las memorias de los protagonistas políticos -Alonso-Castrillo (1996); Hopkin (2000)—.

81 Secretaría de Política Autonómica-PSOE: Reunión entre la Secretaría Federal de Politica Autonómica y senadores socialistas, el día 31 de marzo de 1981, para debatir el tema de la ley de armonización en las CC. AA., ABFPI, 75-E 2, p. 2.

82 Calvo Sotelo (1990): 105. 
en el que las competencias fuesen transferidas, no en un plazo de tres años, sino en un horizonte de veinte o veinticinco ${ }^{83}$.

Los socialistas incidían con fuerza en la tendencia de desconfianza hacia los nacionalismos que se había reforzado desde las elecciones autonómicas de marzo de 1980. Este recelo derivaba en gran medida del temor a que estas fuerzas políticas provocaran la fragmentación de la estructura del sistema bipartidista, amenazando sus posibilidades como alternativa de Gobierno. Una actitud que seguramente decepcionó a buena parte del PSC-PSOE, que a lo largo del mes de marzo — al menos en su línea oficial— se había pronunciado favorable a una respuesta que rechazara la «desnaturalización» de la autonomía catalana ${ }^{84}$. Pese a todo, los socialistas catalanes eran partidarios de una solución que pasaba igualmente por una alianza entre socialistas y centristas, en la que los primeros deberían actuar como garantes de los derechos autonómicos ${ }^{85}$.

Retornando a la gestación de los acuerdos, ambos partidos nombraron en abril una Comisión de Expertos independientes designada de mutuo acuerdo y encabezada por Eduardo García de Enterría - que contaba con gran influencia entre UCD y $\mathrm{PSOE}^{86}$ — para diseñar el «modelo global» del Estado de las autonomías. Según acordaron esta debía establecer algunos puntos esenciales al respecto, como la reconducción de todos los estatutos restantes por la vía del 143 o la homogeneización del sistema para evitar el agravio comparativo y encauzar la gobernabilidad ${ }^{87}$. La Comisión fue constituida el día 7 de abril en una reunión en la que se acordó el método de trabajo de la misma y a la que asistieron miembros del Ejecutivo y del PSOE junto a García de Enterría ${ }^{88}$. Pese a que algunos de sus miembros han insistido en

83 Comisión Ejecutiva Federal del PSOE: Los problemas de la democracia (abril 1981), AHUV, Fons Alfons Cucó, 019/012, pp. 4 y 8.

84 PSC-PSOE: Informe politic del 1er Secretari Joan Reventós all Consell Nacional. 8 de març del 1981. Resolució del Consell Nacional sobre la situació politica del moment, Arxiu del Partit del Socialistes de Catalunya (APSC), 9.1.27.

85 Como también ha apuntado Jaume Muñoz, el PSC y el PSOE mantuvieron posiciones complementarias en la cuestión de la armonización del proceso autonómico (Muñoz, 2019).

86 Herrero de Miñón (1993): 35.

87 «Nota de prensa conjunta de L. Calvo Sotelo y F. González el 3 de abril de 1981», ABFPI, 74-H 4; anexo adjunto a la nota de prensa con lo que parecen ser las bases mínimas para el acuerdo, "Anexo", ABFPI, 74-H 4.

88 «Acuerdo del 7 de abril», ABFPI, 74-H 4. Los miembros designados por el acuerdo de ambas fuerzas fueron: Tomás Ramón Fernández, Luis Cosculluela, Francisco 
señalar la práctica inexistencia de directrices recibidas ${ }^{89}$, sí existieron y tuvieron que ver, especialmente, con la generalización del hecho autonómico, aunque fueron escuetas. Un día antes de nombrar la Comisión se establecieron por escrito algunos aspectos sobre la misma, su funcionamiento y su razón de ser. Este documento de seis páginas hacía una sugerencia detallada de los temas que tratar, demandando el establecimiento de criterios generales para un «desarrollo ordenado» del título VIII; la delimitación del mapa autonómico y de los plazos para su ejecución; el estudio de un «régimen especial para encajar en el sistema general a las dos autonomías ya en marcha (Cataluña y País Vasco), más a Galicia»; o la imposición de requisitos a las futuras Administraciones autonómicas para poder acoger las transferencias. Aunque en el documento se indicaba que la Comisión actuaría con plena independencia y que las instrucciones no debían ser demasiado estrictas, se señalaba que esto se produciría «sin perjuicio, naturalmente, de que solo al grupo político pertenece la decisión final, así como la orientación ulterior del trabajo de la Comisión». De hecho, en un apartado anterior se especificaban dos fases en el desarrollo del trabajo de la Comisión, en la que la primera remitía a la elaboración de una propuesta global «de acuerdo con las instrucciones generales que reciba», y en la segunda se reelaboraría dicha propuesta "a la vista de las decisiones que adopte el escalón político»" ${ }^{90}$.

Desde entonces y hasta la firma de los Acuerdos Autonómicos el 31 de julio de 1981, PSOE y UCD fueron los principales actores del que debía ser un pacto de Estado al que invitaron al resto de fuerzas políticas una vez se había llegado a los consensos básicos de forma bilateral ${ }^{91}$. En todo este tiempo, nunca se cuestionó la racionalización, la generalización, la

Sosa Wagner, Tomás de la Quadra Salcedo, Santiago Muñoz Machado, y Miguel Sánchez Morón.

89 En este sentido se han pronunciado el secretario de la Comisión, Santiago Muñoz Machado, y Tomás Ramón Fernández —Muñoz Machado (2012): 41-42; Alonso y Elordi (1982): 149-.

90 «Nota sobre trabajo de la Comisión de Expertos en el tema autonómico» (6 de abril de 1981), ABFPI, 74-H 4.

91 Los acuerdos no gustaron, sin embargo, al sector crítico de UCD, que llevó al II Congreso - celebrado entre el 6 y el 9 de febrero- una ponencia con una estrategia alternativa que, en palabras de Miguel Herrero de Miñón, permitía «la consolidación de los hechos diferenciales y la congelación en lo que a las restantes autonomías se refiere». En lugar de esto, añadía, "por influencia de un informe técnico que en más de una ocasión he calificado de bufo, se optó por la generalización del sistema sobre el modelo catalán, de acuerdo a las exigencias de simetría propia de los manuales de derecho administrativo» (Herrero de Miñón, 1993): 241. 
igualación y la homogeneización que se iba a imponer desde el Estado, motivo por el cual ni CiU ni el PNV se sentaron a debatir. Sintomáticamente, a la reunión del 24 de febrero entre el monarca y los líderes de UCD, PSOE, PCE y AP no estuvieron invitadas las fuerzas nacionalistas de Cataluña y Euskadi. Y aquella marginación se prolongó, según explicó Calvo Sotelo, porque el PSOE recelaba de una alianza entre UCD y los nacionalismos, especialmente con $\mathrm{CiU}$, pacto, por otra parte, denunciado insistentemente desde el socialismo catalán y español ${ }^{22}$ : «En los últimos días de julio [...] intenté llevar a la mesa de negociación con el PSOE algunas propuestas transaccionales que me había enviado Roca: la posición de Guerra fue de cerrada negativa. Me sorprendió su rigidez: pensé que se temía un acercamiento electoral UCD/CiU»»33.

Finalmente, los principales actores de la negociación fueron los únicos que dieron luz verde a este propósito de uniformización y modernización del Estado, mientras que aquellos grupos que se habían sentado a debatir casi como convidados de piedra, PCE y AP, desestimaron suscribirlos horas antes de sellar el acuerdo ${ }^{94}$. Los comunistas, aunque se mostraron formalmente en desacuerdo con el proyecto, compartían la idea de que la planificación del Estado de las autonomías debía racionalizarse a partir de un pacto de Estado que, eso sí, los incluyera ${ }^{95}$. Solé Tura señaló en el debate parlamentario de 1982 sobre la LOAPA que, aunque compartían la idea de que tras los sucesos de Andalucía era necesario acoger una fórmula general basada en un gran

92 Entre finales de 1980 y principios de 1981 el PSOE llegó, incluso, a formular hipótesis que planteaban su estrategia en materia autonómica a partir del boicot a cualquier posibilidad de acuerdo entre UCD y los nacionalismos, tratando, de paso, de favorecer la ruptura del partido centrista. Aunque no acabaran decantándose por llevar a la práctica estas ideas, el miedo a un acuerdo entre centristas y «nacionalistas» estaba muy presente. PSOE: Formulación de la estrategia a decidir, ABFPI, 82-C 1. Las denuncias a la sintonía de intereses entre CiU y UCD, contrarios a los de la clase obrera, eran, por otra parte, comunes y públicos en el PSOE y el PSC-PSOE desde las elecciones autonómicas.

93 Calvo Sotelo (1990): 109-116. En el mismo sentido, Martín Villa (1984): 194. El periodista Antxon Sarasqueta (1984), sin embargo, reparte la responsabilidad de la marginación de los "nacionalistas", entre socialistas y centristas.

94 Leopoldo Calvo Sotelo admitiría que fue decisión de UCD y del PSOE forjar un acuerdo bilateral una vez no consiguieron sumar a CiU y PNV (Calvo Sotelo, 1990): 115.

95 PCE: Consideraciones del PCE ante «el Informe de la Comisión de Expertos de sobre Autonomias» (4 de junio de 1981), ABFPI, $75-B) 7$ (Conclusiones enviadas al secretario general del PSOE). 
pacto de Estado, este no se produjo en aquellos términos porque su participación se había dado "a posteriori y casi a contrapelo»"

El Proyecto de Ley Orgánica de Armonización del Proceso Autonómico (LOAPA) nació desde el inicio cuestionado. Presentado en octubre de 1981 y aprobado en julio de 1982, no zanjó en ningún caso la polémica, aunque sí sancionó un determinado modelo de Estado a partir de una concepción compartida por PSOE y UCD ${ }^{97}$.

\section{CONCLUSIONES}

Centristas y socialistas pactaron en julio de 1981 un modelo que ordenaba y homogeneizaba el futuro Estado de las autonomías. La cuestión es si aquel modelo se adecuaba a los principios que definían el pensamiento socialista hasta aquellos acuerdos o por el contrario fue fruto de una coyuntura concreta. Es decir, si la forma que adoptó finalmente el Estado autonómico fue producto de un golpe de Estado frustrado y del miedo a la acción de fuerzas antidemocráticas o si, por el contrario, tuvo más que ver con la coincidencia en los intereses - y las lógicas cesiones propias de una negociación que buscaba el consenso- entre dos fuerzas mayoritarias. Tanto Calvo Sotelo como Felipe González han defendido, como no podía ser de otra manera, que el modelo resultante no fue consecuencia del chantaje de fuerzas reaccionarias. El secretario general del PSOE afirmaba a este respecto: «Se ha dicho que la causa inmediata de la puesta en marcha de una dinámica de Pactos Autonómicos y de su derivación normativa, como es el caso de la LOAPA, está en el 23F. No se puede decir eso al Grupo Parlamentario y al Partido que represento, y no creo que sea legítimo decírselo a nadies" ${ }^{98}$.

Pero más allá de estas declaraciones, la documentación analizada prueba que el Partido Socialista compartía por completo un modelo

96 Diario de Sesiones del Congreso de los Diputados, n. ${ }^{\circ}$ 250, 21 de junio de 1982, p. 14506.

97 Concedieron al País Valenciano y a Canarias la posibilidad de alcanzar directamente las competencias de la vía del artículo 151 aunque sus estatutos fueran tramitados por el 143, por medio de dos leyes orgánicas de transferencias: la LOTRAVA y la LOTRACA (Aja, 1996): 125. Aunque buena parte de la LOAPA fue declarada inconstitucional en 1983 por su carácter orgánico y armonizador, el espíritu de la misma fue irreversible (Powell, 2001): 306.

98 Diario de Sesiones del Congreso de los Diputados, n.o 251, 22 de junio de 1982, pp. 14543-14544. 
autonómico que anteponía la unidad, la solidaridad, la homogeneidad, la igualdad y la simetría del Estado por encima del derecho a la diferencia. Un principio que, aun formando parte de su ideario y su programa, siempre se había supeditado a los anteriores. Lo que permitió el 23F fue precisamente la conclusión de un acuerdo que se venía fraguando con altibajos desde finales de 1979 y principios de 1980. Tras la solución del caso vasco y el catalán, fueron los avatares propios de la coyuntura los que evitaron un pacto que se hacía incompatible, de forma inmediata, con intereses territoriales y partidistas que prevalecieron temporalmente. El retraso en el acuerdo se debió en gran medida a que el Partido Socialista se mantuvo a la espera de soluciones satisfactorias y puntuales en territorios como Andalucía o Galicia, y a que actuó teniendo muy presente su estrategia de alternativa de gobierno frente a UCD. Pero de fondo, durante todo este período se fueron estableciendo las bases para un pacto en el que los socialistas no renunciaron a sus convicciones más profundas y que pasaba por la armonización.

\section{BIBLIOGRAFÍA}

Aja, E. (1996). Los principales periodos de desarrollo del Estado autonómico. Anuario Jurídico de La Rioja, 2, 121-144.

Alonso, C. y Elordi, C. (1982). El desafío socialista. Barcelona: Editorial Laia.

Alonso-Castrillo, S. (1996). La apuesta del centro. Historia de UCD. Madrid: Alianza Editorial.

Andrade, J. A. (2012). El PCE y el PSOE en (la) transición. La evolución ideológica de la izquierda durante el proceso de cambio político. Madrid: Siglo XXI.

Archilés, F. (2009). El «olvido» de España. Izquierda y nacionalismo español en la Transición democrática: el caso del PCE. Historia del Presente, 14, 103-122.

- (2016). ¿Atada y bien atada? La cuestión nacional y las culturas políticas españolas (1975-1978). En A. Bosch y I. Saz (eds.). Izquierdas y derechas antes el espejo. Culturas políticas en conflicto (pp. 141-173). València. Tirant Humanidades.

Calvo Sotelo, L. (1990). Memoria viva de la transición. Barcelona: Plaza y Janés; Cambio 16.

Clavero, M. (1980). Forjar Andalucía. Granada: Argantonio, Ediciones Andaluzas.

- (1983). España, desde el centralismo a las autonomías. Barcelona: Planeta.

Company, E. y Arroyo, F. (1989). Historia del socialismo español (vol. 5). Barcelona: Conjunto Editorial.

Culla, J. (1998). Una piedra en el zapato. El nacionalismo catalán en el escenario político español (1976-1998). En X. Bru de Sala y J. Tusell (eds.). España-Catalunya: un diálogo con futuro. Barcelona: Planeta.

De Blas, A. (1978). El problema nacional-regional español en los programas del PSOE y PCE. Revista de Estudios Politicos, 4, 155-170. 
De la Granja, J. L, Beramendi, J. y Anguera, P. (2001). La España de los nacionalismos y las autonomias. Madrid: Síntesis.

De los Santos, J. M. (2002). Andalucía en la Transición (1976-1982). Sevilla: Centro de Estudios Andaluces.

Fajardo, L. (2009). ¿Hacia otro modelo de Estado? Los socialistas y el Estado autonómico. Navarra: Aranzadi.

Gillespie, R. (1991). Historia del Partido Socialista Obrero Español. Madrid: Alianza Universal.

Grandío, E. (2015). El lustro que marcó el camino: el PSOE en Galicia (1974-1978). Historia del Presente, 26, 59-76.

Guerra, A. (1977). XXVII Congreso PSOE. Barcelona: Avance.

- (1985). La Transición democrática en España. Sistema, 68-69, 5-18.

- (2004). Cuando el tiempo nos alcanza (1940-1982). Madrid: Espasa.

Herrero de Miñón, M. (1993). La gestación del sistema autonómico español: claves del sistema constituyente. Revista Vasca de Administración Pública, 36, 29-43. (1993). Memorias de estio. Madrid: Temas de hoy.

Hopkin, J. (2000). El partido de la Transición. Ascenso y caída de la UCD. Madrid: Acento Editorial.

Juliá, S. (1997). Los socialistas en la política española, 1879-1982. Madrid: Taurus.

- (2013). Nación, nacionalidades y regiones en la transición política a la democracia. En A. Morales Moya, J. P. Fusi Aizpurúa y A. de Blas Guerrero (coords.). Historia de la nación y del nacionalismo (pp. 886-902). Barcelona: Galaxia Gutenberg.

Landaberea, E. (2016). Los «nosotros» en la Transición. Memoria e identidad en las cuatro principales culturas politicas del País Vasco (1975-1980). Madrid: Tecnos. Disponible en: https://doi.org/10.4000/bhce.914.

Martín Villa, R. (1984). Al servicio del Estado. Barcelona: Planeta.

Martín, J. (1987). El compromiso constante. Apuntes para una biografia. Las Palmas de Gran Canaria: Partido Socialista Canario-Partido Socialista Obrero Espańol.

Mateos, A. (2007). La Transición del PSOE durante los años setenta. En R. Quirosa-Cheyrouze (coord.). Historia de la Transición en España. Los inicios del proceso democratizador (pp. 285-299). Madrid: Biblioteca Nueva.

- (2017). Historia del PSOE en transición. De la renovación a la crisis, 1970-1988. Madrid: Sílex.

Miccichè, A. (2009). Euskadi socialista. El PSE-PSOE y la Transición en el País Vasco (19761980). Madrid: Pablo Iglesias.

Molinero, C. (2011). La oposición al franquismo y la cuestión nacional. En J. Moreno (ed.). Izquierdas y nacionalismos en la España contemporánea (pp. 235-256). Madrid: Pablo Iglesias.

- y Ysàs, P. (2014). La cuestión catalana. Cataluña en la transición española. Barcelona: Crítica.

— y Ysàs, P. (2018). La Transición. Historia y relatos. Madrid: Siglo XXI.

Muñoz, J. (2019). Perseguint la llibertat. La construcció de l'espai socialista a Catalunya, $1945-$ 1982. Barcelona: Avenç.

Muñoz Machado, S. (2012). Informe sobre España. Repensar el Estado o destruirlo. Crítica: Barcelona. 
Núñez Seixas, X. M. (2010). Patriotas y demócratas: el discurso nacionalista español después de Franco. Madrid: La Catarata.

Peces-Barba, G. (1988). La elaboración de la Constitución de 1978. Madrid: Centro de Estudios Constitucionales.

Powell, C. (2001). España en democracia, 1975-2000. Barcelona: Plaza y Janés.

Quiroga, A. (2009). Coyunturas críticas. La izquierda y la idea de España durante la Transición. Historia del Presente, 13, 21-40.

Rubio, J. A. (2004). Los nacionalismos vascos y catalanes ante la LOAPA: Ajustes y desajustes en los inicios del Estado de las autonomías. Historia Actual Online, 5, 65-80.

Ruiz, M. (2005). La conquista del Estatuto de Autonomía para Andalucia (1977-1982). Sevilla: Instituto Andaluz de Administración Pública.

Sánchez, D. (2009). La Unión de Centro Democrático y la idea de España: la problemática reelaboración de un discurso nacionalista para un contexto democrático. Historia del Presente, 13, 7-20.

Sarasqueta, A. (1984). De Franco a Felipe. (España 1975-1985). Barcelona: Plaza y Janés. 